\title{
Evaluasi Program Pemuliaan Berdasarkan Parameter Genetik dan Fenotipik Pada Sapi Peranakan Ongole
}

\author{
Evaluation of Breeding Program based on Genetic and Phenotypic Parameters of Ongole Crossbred
}

\author{
A. Irianto, Muladno, \& A. Gunawan* \\ Departemen Ilmu Produksi dan Teknologi Peternakan, Fakultas Peternakan, Institut Pertanian Bogor \\ Jl. Agatis, Kampus IPB Darmaga Bogor 16680, Indonesia \\ *Corresponding author: agunawan@apps.ipb.ac.id \\ (Received 15-07-2021; Revised 12-08-2021; Accepted 13-09-2021)
}

\begin{abstract}
The field station of the School for Smallholder Community, Sekaran Village, Kasiman District is one of the places for beef cattle development in Bojonegoro Regency. Sekaran Field Station has several breeds of cattle, including Ongole Crossbred. Ongole Crossbreeds have a large population in the Sekaran School for Smallholder Community with a population of $38 \%$. Evaluation of breeding programs is based on genetic parameters and can be used to obtain the latest information on the successful implementation of breeding programs in a population of livestock. The aim of this study was to evaluate the development program of Ongole Crossbreed cattle at the Sekaran School for Smallholder Community field station using genetic and phenotypic parameters. This study uses a survey method based on questionnaires by conducting interviews with farmers. The data observed were recorded data from 190 heads of Ongole Crossbreeds. The parameters observed were breeding values, genetic and phenotypic correlations, as well as genetic and phenotypic patterns. The results showed that the highest estimation of breeding value in Ongole Crossbred was 5.71 (6 heads) and the lowest was 0.10 ( 2 heads). The genetic correlation of age at first giving birth, calving distance and empty period ranged from $\mathbf{- 0 . 0 3 - 0 . 1 3}$. The phenotypic correlation of the three reproductive traits ranged from -0.12-0.09. The genetic patterns of age at first giving birth, calving distance and empty period were $\mathbf{- 0 . 9 7}$ months/year, $\mathbf{- 2 . 5 1}$ days/year and 0.05 days/ year, respectively. The phenotypic patterns of the three reproductive traits were 36 months/year, 388 days/year and 84 days/year, respectively. Based on the results of the evaluation of the breeding program using genetic and phenotypic parameters, the development of Ongole Peranakan cattle needs to be continued by implementing good and digital-based management in order to provide success in the Ongole Crossbred development program at the Sekaran field station of the School for Smallholder Community.
\end{abstract}

Keywords: Genetics, phenotypic, breeding, smallholder livestock, Ongole crossbreeds

\section{ABSTRAK}

Stasiun lapang Sekolah Peternakan Rakyat Desa Sekaran Kecamatan Kasiman merupakan salah satu tempat pengembangan sapi potong di Kabupaten Bojonegoro. Stasiun Lapang SPR Sekaran memiliki beberapa populasi bangsa sapi diantaranya adalah sapi Peranakan Ongole. Sapi Peranakan Ongole cukup banyak populasinya di Stasiun lapang Sekolah Peternakan Rakyat Sekaran dengan populasi sebanyak 38\%. Evaluasi program pemuliaan berdasarkan parameter genetik dan dapat digunakan untuk mendapatkan informasi terbaru mengenai keberhasilan penerapan program pemuliaan dalam satu populasi ternak. Tujuan penelitian adalah untuk mengevaluasi program pengembangan sapi Peranakan Ongole di Stasiun lapang Sekolah Peternakan Rakyat Sekaran menggunakan parameter genetik dan fenotipik. Penelitian ini menggunakan metode survei berdasarkan kuisioner dengan melakukan wawancara kepada peternak. Data yang diamati adalah data hasil recording dari 190 ekor indukkan sapi Peranakan Ongole. Parameter yang diamati adalah nilai pemuliaan, korelasi genetik dan fenotipik, serta pola genetik dan fenotipik. Hasil penelitian menunjukkan bahwa pendugaan nilai pemuliaan tertinggi pada sapi Peranakan Ongo didapatkan 5.71 (6 ekor) dan terendah 0.10 (2 ekor). Korelasi genetik umur pertama kali melahirkan, jarak beranak dan masa kosong berkisar antara -0.030.13. Korelasi fenotipik dari ketiga sifat reproduksi tersebut berkisar antara -0.12-0.09. Pola genetik umur pertama kali melahirkan, jarak beranak dan masa kosong masing-masing -0.97 bulan/tahun, -2.51 hari/tahun dan 0.05 hari/tahun. Pola fenotipik dari ketiga sifat reproduksi tersebut masing-masing 36 bulan/tahun, 388 hari/tahun dan 84 hari/tahun. Berdasarkan hasil evaluasi program pemuliaan dengan menggunakan parameter genetik dan fenotipik maka pengembangan sapi Peranakan Ongole perlu dilanjutkan dengan menerapkan manajemen yang baik dan berbasis digital agar memberikan keberhasilan dalam program pengembangan sapi Peranakan Ongole di Stasiun lapang Sekolah Peternakan Rakyat Sekaran.

Kata kunci: Genetik, fenotipik, pemuliaan, peternakan rakyat, sapi peranakan ongole 


\section{PENDAHULUAN}

Stasiun Lapang Sekolah Peternakan Rakyat (SLSPR) Sekaran Kabupaten Bojonegoro merupakan salah satu tempat pengembangan sapi potong dengan menggunakan sistem bisnis kolektif yang semua ternaknya dimiliki oleh peternak kecil. SL-SPR Sekaran telah berdiri sejak tahun 2015. Terdapat beberapa bangsa sapi di SL-SPR Sekaran. Salah satu bangsa sapi yang memiliki jumlah populasi cukup banyak yakni sapi Peranakan Ongole (PO) dengan presentasi $38 \%$.

Sapi Peranakan Ongole merupakan salah satu sapi lokal Indonesia yang memiliki kelebihan dalam produktivitas maupun reproduktivitas. Sapi PO merupakan sapi hasil persilangan antara sapi Jawa dengan sapi Ongole yang berasal dari India yang dikembangkan di Pulau Sumba sekitar tahun 1930 dan telah terbentuk sapi PO yang mendekati sapi Ongole murni (Hardjosubroto 1994). Sapi PO merupakan tipe sapi dwiguna, tahan serangan penyakit parasit, temperatur udara panas, kelembapan udara rendah, daerah kering, pakan terbatas kualitas dan kuantitasnya, serta efesien dalam reproduksi dengan kondisi peternakan rakyat (Aryogi et al. 2007), juga sapi PO memiliki daya adaptasi yang baik terhadap kondisi lingkungan peternakan tradisional (Astuti 2004; Desinawati dan Isnaini 2010; Nuryadi dan Wahjuningsih 2011; Siswanto et al. 2013). Hasil penelitian Yulianto et al. (2014) melaporkan penampilan reproduksi sapi PO lebih baik dan efisien dibandingkan dengan sapi Peranakan Limousin.

Salah satu kajian yang perlu dilakukan dalam mendukung program pengembangan sapi potong di SL-SPR adalah evaluasi program pemuliaan yang berguna sebagai bahan evaluasi pengembangan sapi potong di lingkungan SPR Sekaran. Evaluasi program pemuliaan dilakukan oleh banyak peternakan sapi potong sebagai laporan kemajuan sebuah program yang diterapkan di suatu wilayah. Seleksi banyak digunakan oleh peternak sebagai salah satu parameter dalam keberhasilan program pengembangan sapi potong. Parameter genetik dan fenotipik sering digunakan dalam beberapa penelitian sebagai parameter dalam evaluasi program pemuliaan. Parameter genetik sebagai metode dalam mengevaluasi program pemuliaan sangatlah penting sebagai dasar acuan dalam keberhasilan program.

Parameter genetik yang digunakan dalam evaluasi program pemuliaan di peternakan rakyat diantaranya adalah nilai pemuliaan, perhitungan nilai korelasi genetik dan fenotipik, serta nilai pola genetik dan fenotipik dari suatu sifat yang diduga dapat memberikan keuntungan dalam program pemuliaan. Evaluasi program pemuliaan menggunakan pola genetik telah dilakukan oleh Bernardes et al. (2015) pada sifat reproduksi guna mengevaluasi program pengembangan sapi lokal.

Nilai pemuliaan (NP) atau biasa disebut Estimated Breeding Value (EBV) merupakan salah satu cara yang dapat digunakan sebagai metode dalam mengevaluasi mutu genetik produksi maupun reproduksi ternak untuk mendapatkan nilai yang unggul sebagai dasar dalam program seleksi. Nilai pemuliaan didefinisikan sebagai total kemampuan genetik ternak dalam program pemuliaan untuk sifat tertentu (Salem dan Hammoud 2016). Nilai pemuliaan tidak dapat diukur langsung namun dapat dilakukan estimasi untuk mendapatkan nilai pemuliaan pada setiap ternak (Prihandini et al. 2011). Keakuratan pendugaan nilai pemuliaan sangatlah penting guna memberikan penentu arah perbaikan mutu genetik sebagai parameter keberhasilan (Lee et al. 2015). Evaluasi program pemuliaan pada sapi lokal seperti sapi Bali menggunakan parameter genetik telah dilakukan oleh Gunawan et al. (2011); Sonbait et al. (2011); Riyanto et al. (2015). Menurut Lopez et al. (2020) bahwa parameter genetik seperti nilai pemuliaan, pola genetik, heritabilitas, sifat reproduksi umur pertama beranak, jarak bernak dan masa kosong serta beberapa parameter lainnya dapat digunakan sebagai kajian dalam mengevaluasi program pemuliaan sapi lokal. Penelitian terdahulu tidak banyak yang menggunakan data dari peternakan rakyat sebagai objek dalam evaluasi program pengembangan ternak.

Oleh karena itu, perlu dilakukan evaluasi program pemuliaan pada peternakan rakyat berdasarkan parameter genetik dan fenotipik dengan harapan mampu memberikan informasi terbaru mengenai program pengembangan sapi lokal yang ada di peternakan rakyat baik kemajuannya maupun teknologi terbaru yang dapat diterapkan. Penelitian ini bertujuan untuk mengevaluasi program pengembangan sapi PO di SL-SPR Sekaran dengan menggunakan parameter genetik dan fenotipik sebagai kriteria dalam evaluasi program pemuliaan.

\section{MATERI DAN METODE}

\section{Materi}

Penelitian ini menggunakan data berdasarkan hasil recording pada Stasiun Lapang Sekolah Peternakan Rakyat (SL-SPR) Institut Pertanian Bogor di Desa Sekaran, Kecamatan Kasiman Kabupaten Bojonegoro. Penelitian ini menggunakan metode survei, dengan mengambil sampel dari populasi dengan menggunakan kuisioner sebagai alat pengumpul data (Singarimbun dan Effendi 1989). Data yang digunakan berasal dari pencatatan melalui wawancara mulai tahun 2008-2019. Data yang dikumpulkan berupa data primer dari hasil survei dengan menggunakan kuisioner dan data sekunder dari hasil penelitian sebelumnya baik dari BPS Kabupaten Bojonegoro atau hasil recording mandiri oleh peternak sebelumnya sebagai bahan acuan dan untuk mengetahui data jumlah populasi ternak dan kondisi wilayah.

Pengumpulan data dilakukan pada tiga Dusun yakni Ngantru, Jarkulon dan Jarwetan. Survei dilakukan guna mengetahui jumlah populasi sapi PO dan jenis bangsa sapi lainnya serta kondisi terkini pada lingkungan SL-SPR Sekaran. Jumlah indukan sapi PO yang berhasil masuk dalam recording sebanyak 190 ekor digunakan sebagai dasar evaluasi program pemuliaan. Pengambilan data dilakukan pada bulan Agustus-Desember 2019. Data yang direkap meliputi identitas peternak, informasi ternak meliputi asal, bangsa, tanggal lahir, identitas tetua, jumlah anak dan status kepemilikan. Data kondisi ternak berupa setatus kebuntingan, nilai kondisi tubuh, kondisi kesehatan 
serta data produktivitas ternak berdasarkan bobot badan dan nilai ukuran tubuh (lingkar dada).

\section{Parameter Penelitian}

Parameter yang dilakukan pengukuran dalam penelitian ini meliputi: 1) nilai pemuliaan: nilai yang menunjukkan posisi individu dalam populasi (Kaygisiz 2013); 2) korelasi genetik dan fenotipik: hubungan antara dua sifat atau lebih (Karnaen 2008); 3) pola genetik dan fenotipik: merupakan pola yang mencerminkan perubahan pada sifat genetik dan fenotipik dalam populasi pada periode tertentu (Zishiri et al. 2010).

\section{Analisis Data}

Pendugaan nilai pemuliaan (Estimated Breeding Value) pada penelitian ini menggunakan rumus menurut Hardjosubroto (1994):

$$
\mathrm{NP}=\mathrm{h}^{2}(\mathrm{P}-\overline{\mathrm{P}})+\overline{\mathrm{P}}
$$

\section{Keterangan:}

$\mathrm{NP}=$ Estimasi Nilai Pemuliaan

$\mathrm{h}^{2} \quad=$ Angka pewarisan (heritabilitas) untuk sifat reproduksi

$\mathrm{P} \quad=$ Performans individu

$\mathrm{P} \quad=$ Rata-rata performans populasi

Pendugaan nilai korelasi genetik dan fenotipik terkait dengan dengan sifat reproduksi meliputi umur pertama beranak (age at first calving) atau AFC, jarak beranak (calving interval) atau CI dan masa kosong (days open) atau DO menggunakan rumus Becker (1992):

$$
r p=\frac{r g=\frac{\operatorname{covo}+\text { cove }}{\delta o x^{2} \delta y^{2}}}{\operatorname{covo}+\text { cove }} \sqrt{\sqrt{\left(\delta^{2} o x+\delta^{2} e x\right) \times\left(\delta^{2} o y+\delta^{2} e y\right)}}
$$

\section{Keterangan:}

$$
\begin{array}{ll}
\mathrm{rg} & =\text { Korelasi genetik } \\
\mathrm{rp} & =\text { Korelasi fenotipik } \\
\mathrm{O} & =\text { Peragam komponen genetik } \\
\mathrm{e} & =\text { Ragam komponen sifat pertama } \\
\mathrm{x} \text { atau y } & =\text { Ragam komponen sifat kedua }
\end{array}
$$

Pendugaan pola genetik dan fenotipik sifat AFC, CI dan DO berdasarkan rata-rata nilai regresi sifat $\mathrm{AFC}, \mathrm{CI}$, dan DO dengan NP menggunakan rumus Filho et al. (2005):

$$
\mathrm{Y}=\mathrm{a}+\mathrm{bX}
$$

\section{Keterangan:}

$\mathrm{Y}=$ Pola genetik dan fenotipik dugaan dari sifat $\mathrm{AFC}, \mathrm{CI}$ dan DO dengan nilai pemuliaan

$\mathrm{a}=$ Intercept

$\mathrm{X}=$ Tahun lahir induk

$\mathrm{B}=$ Koefisien regresi untuk Y pada $\mathrm{X}$

\section{HASIL DAN PEMBAHASAN}

\section{Pendugaan Nilai Pemuliaan}

Nilai pemuliaan pada penelitian ini diperoleh berdasarkan estimasi nilai pemuliaan sifat reproduksi AFC atau biasa disebut sebagai umur pertama kali beranak pada indukan (Tabel 1). Selanjutnya masing-masing indukan diberikan grade sebagai penanda. Prihandini et al. (2011) menyatakan bahwa nilai pemuliaan tidak dapat diukur langsung namun dapat dilakukan estimasi atau pendugaan nilai pemuliaan pada setiap ternak.

Tabel 1. Sepuluh Indukkan sapi PO terbaik berdasarkan nilai pemuliaan sifat reproduksi AFC

\begin{tabular}{lccc}
\hline No. ID & $\begin{array}{c}\text { Umur } \\
\text { (Tahun) }\end{array}$ & $\begin{array}{c}\text { Jumlah Kelahiran } \\
\text { (Ekor) }\end{array}$ & $\begin{array}{c}\text { Nilai } \\
\text { Pemuliaan } \\
\text { (Peringkat) }\end{array}$ \\
\hline Katin2 & 7 & 4 & $5.71(1)$ \\
Minto1 & 7 & 3 & $5.71(2)$ \\
Mojo1 & 7 & 3 & $5.71(3)$ \\
Dedi1 & 10 & 8 & $5.71(4)$ \\
Parni1 & 10 & 5 & $5.71(5)$ \\
Trisno1 & 10 & 5 & $5.71(6)$ \\
Sukar3 & 10 & 3 & $4.87(7)$ \\
Tasuwi2 & 8 & 2 & $4.87(8)$ \\
Lasmin1 & 10 & 4 & $4.87(9)$ \\
Rimanto1 & 10 & 5 & $4.87(10)$ \\
Surip1 & 5 & 2 & $0.10(53)$ \\
Yanto (RT)1 & 7 & 4 & $0.10(54)$ \\
\hline
\end{tabular}

Hasil penelitian ini didapatkan nilai pemuliaan dari indukkan yang memiliki grade A sebanyak 54 ekor diambil dari $20 \%$ jumlah populasi berdasarkan teori program pemuliaan (Martojo 2015). Nilai pemuliaan tertinggi yakni sebesar 5.71 dengan jumlah 6 ekor indukkan, sedangkan nilai pemuliaan yang paling rendah berada pada angka 0.10 dengan jumlah 2 ekor indukkan. Menurut laporan FaidAllah et al. (2016) nilai pemuliaan diekspresikan sebagai penyimpangan dari rata-rata populasi dan indukan diberi peringkat berdasarkan kemampuan genetiknya.

Penggunaan rangking atau grade pada indukkan sapi PO dapat memberikan kemudahan dalam pengembangan program pemuliaan, sehingga akan diketahui ternak mana yang mampu berkembang dengan baik dan ternak mana yang harus dikeluarkan dari populasi atau telah masuk masa afkir. Keberhasilan program pemuliaan ternak dapat bergantung pada pendugaan nilai pemuliaan yang dihasilkan dari setiap individu ternak.

\section{Korelasi Genetik dan Fenotipik Sifat AFC, CI, dan DO}

Nilai korelasi genetik sifat AFC, CI dan DO sapi PO yang didapatkan pada penelitian ini berkisar antara $-0.03-0.13$. Korelasi genetik yang memiliki nilai tertinggi (0.13) yakni antara DO $\left({ }^{\mathrm{r}} \mathrm{G}\right)$ dan CI $\left({ }^{\mathrm{r}} \mathrm{F}\right)$. Hasil penelitian yang dilaporkan oleh Faraji-Arough et al. (2011) pada sapi Holstein Iran dihasilkan nilai korelasi genetik antara -0.92- 
0.53. Nilai korelasi antara DO (rG) dan CI (rF) termasuk dalam kategori rendah hal tersebut sejalan dengan laporan Warwick et al. (1990) bahwa nilai korelasi diantara sifatsifat yang memiliki nilai antara 0.01-0.24 termasuk kedalam kategori rendah. Nilai korelasi yang rendah ini diduga dipengaruhi oleh faktor gen dari kedua sifat sehingga memberikan nilai yang rendah pada korelasi antara DO dan CI. Penelitian ini sejalan dengan laporan Hakim et al. (2007) bahwa nilai korelasi yang rendah menunjukkan bahwa gen yang mempengaruhi kedua sifat tersebut masih sangat sedikit dan tidak dapat digunakan sebagai tolak ukur keberhasilan program seleksi.

Korelasi fenotipik pada tiga sifat AFC, CI dan DO sapi PO dalam penelitian ini berkisar antara -0.12-0.09 (Tabel 2). Nilai korelasi tertinggi (0.09) berada antara AFC $\left({ }^{\mathrm{r}} \mathrm{G}\right)$ dan DO $\left({ }^{\mathrm{r}} \mathrm{F}\right)$. Nilai korelasi ini termasuk dalam kategori rendah (Warwick et al. 1990). Hal ini diduga dipengaruhi oleh jumlah sampel ternak. Sejalan dengan laporan Warwick et al. (1990) bahwa untuk mendapatkan hasil maksimal dalam penelitian estimasi disarankan menggunakan data yang lebih besar dengan cakupan lebih dari 500 data. Selain itu, diduga faktor genetik dan lingkungan mempengaruhi nilai korelasi antara sifat AFC dan DO. Hal ini sejalan dengan laporan Gunawan et al. (2008) bahwa faktor genetik ternak menentukan kemampuan seekor ternak, sedangkan faktor lingkungan memberi kesempatan kepada ternak untuk menampilkan kemampuannya.

Tabel 2. Korelasi genetik dan fenotipik (r) sifat AFC, CI dan DO

\begin{tabular}{lccc}
\hline Sifat Reproduksi & AFC $\left({ }^{\mathrm{r}} \mathrm{F}\right)$ & CI $\left({ }^{\mathrm{r}} \mathrm{F}\right)$ & $\mathrm{DO}\left({ }^{\mathrm{r}} \mathrm{F}\right)$ \\
\hline AFC $\left({ }^{\mathrm{r}} \mathrm{G}\right)$ & - & -0.12 & 0.09 \\
$\mathrm{CI}\left({ }^{\mathrm{r}} \mathrm{G}\right)$ & -0.03 & - & 0.06 \\
$\mathrm{DO}\left({ }^{\mathrm{r}} \mathrm{G}\right)$ & 0.06 & 0.13 & - \\
\hline
\end{tabular}

${ }^{\mathrm{r}} \mathrm{G}$ : korelasi genetik; ${ }^{\mathrm{r}} \mathrm{F}$ : korelasi fenotipik

\section{Pola Genetik Sifat AFC, CI, dan DO}

Pola genetik sifat AFC, CI dan DO pada sapi PO mengalami fluktuasi dari hasil penelitian yang diamati dari tahun 2008-2019. Data pola genetik dari ketiga sifat reproduksi tersebut hampir memiliki pola yang sama. Pola genetik sifatAFC pada tahun 2008 hingga 2015 menunjukkan peningkatan yang cukup signifikan dengan angka masingmasing -3.25 dan 0.19, sedangkan tahun 2015, 2016, 2017 dan 2018 mengalami fluktuasi dengan nilai masing-masing
$0.19,0.12,0.14$ dan 0.13 . Pola genetik sifat AFC pada tahun 2018 hingga 2019 kembali menurun dengan nilai masingmasing 0.13 dan 0.10 dengan rata-rata pertahun -0.97 bulan/ tahun. Penelitian ini berbanding terbalik dengan laporan Ibrahim et al. (2009) dan Solemani-Baghshah et al. (2014) pada sapi Holstein bahwa pola genetik sifat AFC masingmasing adalah 0.02 dan 0.07 bulan/tahun. Laporan tersebut lebih rendah dibandingkan laporan penelitian Canaza-Cayo et al. (2016) bahwa nilai pola genetik sifat AFC pada sapi Brazil yakni 0.13 bulan/tahun. Pola genetik sifat AFC sapi PO yang fluktuasi pada hasil penelitian ini dapat dipengaruhi oleh manajemen peternakan yang belum dilakukan dengan baik. Hal tersebut sejalan dengan hasil penelitian Bernardes et al. (2015) bahwa penggunaan strategi manajemen yang baik dapat memberikan pengaruh pada nilai AFC.

Pola genetik sifat CI sapi PO yang diamati dari tahun 2008 hingga 2019 mengalami fluktuasi yang cukup signifikan (Gambar 1). Berdasarakan data yang diperoleh teridentifikasi adanya tren peningkatan pola genetik sifat CI pada tahun 2008-2013 dengan nilai -12.91 hingga 5.40 dan mengalami fluktuasi dari tahun 2014, 2015, 2016, 2017 dan 2018 dengan nilai masing-masing -4.16, 1.12, $-3.99,6.38$, dan 1.98, sedangkan pada tahun 2019 berada pada angka 1.80 berbeda lebih rendah dibandingkan tahun 2016 yang mencapai angka 6.38 dengan rata-rata -2.51 hari/ tahun. Lebih tinggi dibandingkan hasil penelitian SolemaniBaghshah et al. (2014) pada sapi Holstein yakni -0.56 dan Ibrahim et al. (2009) pada sapi Holstein Herd dimana nilai rata-rata CI 0.06 hari/tahun. Menurut laporan Canaza-Cayo et al. (2016) bahwa program genetik yang dirancang dengan baik memiliki dampak positif pada nilai tren CI.

Data pola genetik sifat DO sapi PO yang diamati pada tahun 2008-2019 menunjukkan pola yang hampir mirip dengan sifat AFC dan CI (Gambar 1). Pola genetik sifat DO dari tahun 2008-2013 mengalami peningkatan yang cukup signifikan dengan angka nilai -0.27 hingga 0.05 , sedangkan pada tahun 2014, 2015, 2016, 2017 dan 2018 mengalami fluktuasi dengan nilai yang diperoleh $0.02,-0.11,0.05,-0.12$ dan -0.08. Sedangkan pada tahun 2019 pola genetik sifat DO tersebut yakni 0.13 dengan rata-rata 0.05 hari/tahun. Nilai pola genetik sifat DO sapi PO pada penelitian ini lebih tinggi dibandingkan dengan laporan Solemani-Baghshah et al. (2014) bahwa nilai pola genetik sifat DO pada sapi Holstein yakni 0.02 hari/tahun. Berbeda lebih tinggi dengan laporan Abdallah et al. (2000) pada sapi Holstein bahwa rata-rata pola genetik sifat DO pada penelitiannya yakni 1.10 hari/

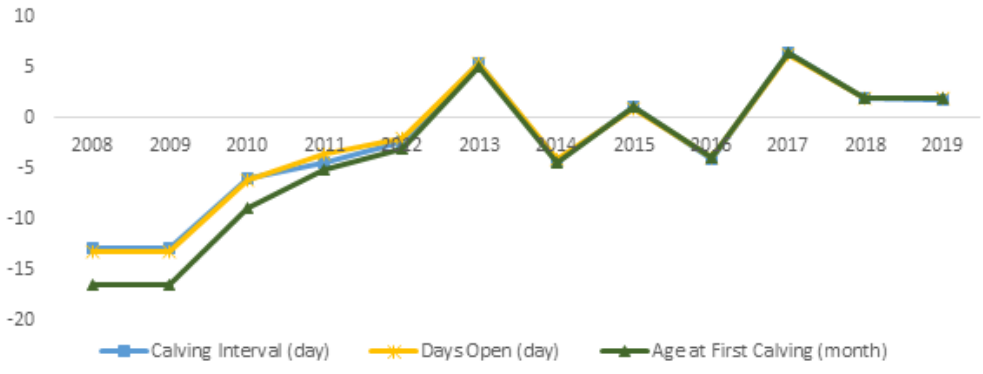

Gambar 1. Pola genetik sifat AFC, CI dan DO sapi PO 
tahun. Hasil penelitian ini menunjukan bahwa pola genetik sifat DO sapi PO mengalami peningkatan yang cukup baik jika dilihat dari data rataan yang diperoleh. Aghajari et al. (2015) melaporkan bahwa sifat DO pada sapi Holstein Iran memiliki rataan nilai pemuliaan yang meningkat sebesar 0.08 hari/tahun dari data awal ( -0.17 hari/tahun)

\section{Pola Fenotipik Sifat AFC, CI dan DO}

Pola fenotipik sifat AFC, CI dan DO sapi PO pada pengamatan antara tahun 2008-2019 terlihat cenderung lebih datar atau statis (Gambar 2). Dilihat dari tahun 2008 sifat AFC cukup mengalami peningkatan walaupun tidak signifikan dilihat dari pola fenotipik yang dihasilkan (Gambar 2). Pola fenotipik sifat AFC tahun 2008 dengan 28 bulan atau 840 hari meningkat hingga tahun 2019 menjadi 40 bulan atau 1200 hari dengan rata-rata 36 bulan/tahun. Berbeda dengan laporan Konkruea et al. (2017) pada sapi Thailand Holstein dengan pola fenotipik sifat AFC yang menurun dari tahun 1993 hingga 1997. Ibrahim et al. (2009) melaporkan bahwa penurunan pola fenotipe sifat AFC dapat disebabkan oleh pengelolaan pedet dan sapi dara yang lebih baik serta kesadaran akan pentingnya nilai ekonomis beranak pertama lebih awal. Penurunan pola fenotipik sifat AFC juga dilaporkan oleh Faraji-Arough et al. (2011) pada sapi Holstein Iran, Gunawan et al. (2011) pada sapi Bali dan Deljoo Isaloo et al. (2012) pada sapi Holstein Iran. Hal tersebut dapat disebabkan oleh manajemen yang baik dilakukan pada umur perkawinan dan beranak pertama sebagai salah satu bagian penting dari program pemuliaan.

Pola fenotipik sifat CI sapi PO dilihat dari tahun 2008 hingga 2019 mengalami peningkatan namun tidak signifikan (Gambar 2). Pola fenotipik sifat CI pada tahun 2008 yakni selama 365 hari dan meningkat menjadi 409 hari pada tahun 2013. Selanjutnya pada tahun 2014 hingga 2019 kembali menunjukkan pola yang sama seperti awal pada tahun 2008-2013. Pola fenotipik sifat CI pada tahun 2014 mencapai 385 hari dan meningkat menjadi 396 hari pada tahun 2019 dengan rata-rata 388 hari/tahun. Peningkatan pola fenotipik sifat CI juga dilaporkan Solemani-Baghshah et al. (2014) pada sapi Holstein, sedangkan hasil penelitian Ansari-Lari et al. (2009) pada sapi Holstein dan Deljoo Isaloo et al. (2012) pada sapi Holstein Iran dilaporkan mengalami penurunan. Peningkatan dan penurunan yang terjadi pada pola fenotipik sifat CI diduga dapat dipengaruhi oleh sistem dan manajemen perkawinan yang dilakukan.
Hasil penelitian pada pola fenotipik sifat DO sapi PO mulai tahun 2008-2019 sedikit mengalami fluktuasi tetapi cenderung stabil Pola fenotipik sifat DO pada tahun 2008 dengan angka 83 hari sedikit naik menjadi 85 hari pada tahun 2013. Selanjutnya pada tahun 2014 dengan angka 84 hari, sedangkan tahun 2019 hanya mencapai angka 85 hari. Hal ini dapat dikatakan berpola datar atau tidak ada perubahan yang terlihat signifikan dengan rata-rata 84 hari/tahun. Hal tersebut dapat dipengaruhi oleh sifat CI yang memberikan dampak pada DO sehingga memiliki pola fenotipik yang kurang lebih sama. Aghajari et al. (2015) menyatakan bahwa penurunan sifat DO dapat dipengaruhi oleh adanya faktor peternak yang ingin mendapatkan keuntungan lebih banyak. Selain itu, menurut Zambrano dan Echeverri (2014) bahwa sifat DO sangat bergantung pada pakan ternak serta manajemen kesehatan dan reproduksi yang baik. Oleh sebab itu hasilnya sering berbeda-beda.

\section{KESIMPULAN}

Evaluasi program pemuliaan sapi PO berdasarkan parameter genetik dan fenotipik didapatkan nilai pemuliaan tertinggi sebesar 5.71 dan terendah dengan nilai 0.10 . Nilai korelasi genetik dan fenotipik sifat AFC, CI dan DO termasuk dalam kategori rendah sehingga sifat-sifat tersebut tidak direkomendasikan sebagai kriteria seleksi. Pola genetik dari ketiga sifat reproduksi tersebut masing-masing dengan nilai rata-rata -0.97 bulan/tahun, -2.51 hari/tahun dan 0.05 hari/tahun sedangkan pola fenotipik masing-masing dengan nilai rata-rata 36 bulan/tahun, 388 hari/tahun dan 84 hari/ tahun. Pola genetik dan fenotipik memiliki pola yang mirip dimana terjadi peningkatan dan juga fluktuasi pada periode program sehingga evaluasi perlu dilakukan secara bertahap agar diperoleh informasi terbaru sebagai dasar acuan dalam keberhasilan program pemuliaan.

\section{UCAPAN TERIMA KASIH}

Ucapan terima kasih disampaikan kepada Kementrian Riset Teknologi dan Badan Riset Inovasi Nasional (KEMENRISTEK-BRIN) dalam Skema Penelitian Perguruan Tinggi (PTUPT) No : 1/E1/KP.PTNBH/2021 yang telah memberikan pendanaan dalam penelitian ini.

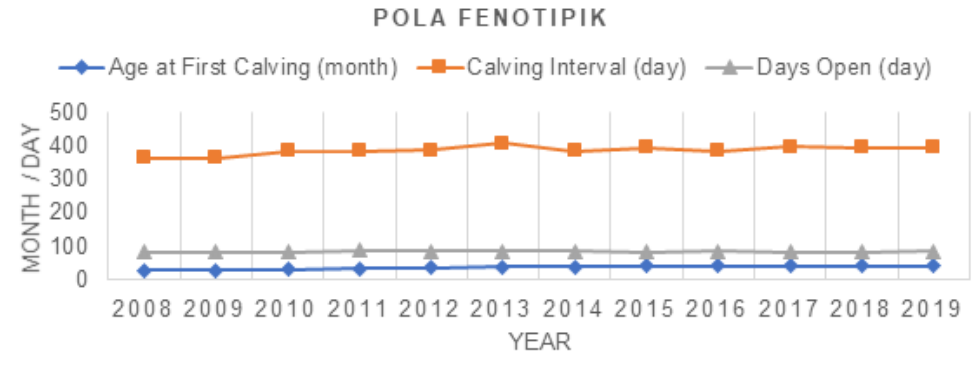

Gambar 2. Pola fenotipik sifat AFC, CI dan DO sapi PO 


\section{DAFTAR PUSTAKA}

Abdallah, J. M., \& B. T. Mc. Daniel. 2000. Genetic parameters and trends of milk, fat, days open and body weight after calving in North Carolina experimental Herds. J. Dairy. Sci. 83:1364-1370.

Aghajari, A., A. A. Mehrgardi, R. Tahmasbi, \& M. Moghbeli. 2015. Genetic and phenotypic trends of productive and reproductive traits in Iranian Holstein dairy cattle of Isfahan Province. IJAS. 5(4): 819-825.

Ansari- Lari. M., M. Rezagholi, \& M. Reiszadeh. 2009. Trends in calving age and calving intervals for Iranian Holstain in Fars province, Southern Iran. Trop. Anim. Health.Prod. 41:1283-1288.

Aryogi, E., Romjali, Mariyono, \& Hartati. 2007. Karakteristik Plasma Nutfah Sapi Potong Lokal Indonesia. Loka Penelitian Sapi Potong Pusat Penelitian dan Pengembangan Peternakan Badan Penelitian dan Pengembangan Pertanian, Grati (Laporan Penelitian).

Astuti, M. 2004. Potensi dan Keragaman Sumberdaya Genetik Sapi Peranakan Ongole (PO). Wartazoa. 14:98-106

Atabany A., B. P. Purwanto, T. Toharmat, \& A. Anggraeni. 2011. Hubungan masa kosong dengan produktifitas pada sapi perah Frisian Holstein di Baturaden, Indonesia. Media Peternakan Fakultas Peternakan, Institut Pertanian Bogor. 34(2):77-82.

Becker, W. A. 1992. Manual of Quantitative. Genetics, 4th edition. Washington (US): Students Book Corporation, Pullman.

Bernardes, P. A., D. A. Grossi, R. P. Savegnago, M. E. Buzanskas, I. Urbinati, L. A. F. Bezerra, R. B. Lobo, \& D. P. Munari. 2015. Estimated of genetic parameters and genetic trends for reproductive traits and weaning weight in Tabapua cattle. J. Anim. Sci. 93:5175-5185.

Canaza-Cayo, A. W., J. A. Cobuci, P. A. Lopes, Torres RdA, M. F. Martins, Daltro DdS, \& M. V. G. B. da Silva. 2016. Genetic trend estimates for milk yield production and fertility traits of the Girolando cattle in Brazil. J. Livestock Science. 190:113-122.

Deljoo-Isaloo, H. A., \& M. Pasha-Eskandari-Nasab. 2012. The estimationngenetic and environmental parameters and genetic and phenotype and genetic trend strad for reproduction traits of Holstein cows was Khoramdare Culture Technology. J. Anim. Sci. 92:5258.

Desinawati, N., \& N. Isnaini. 2010. Penampilan reproduksi sapi Peranakan Simmental di Kabupaten Tulungagung Jawa Timur. Ternak Trop. 11:41-47.

DO, C., N. Wasana, K. Cho, Y. Choi, T. Choi, B. Park, \& D. Lee. 2013. The effect age at first calving and calving interval on productive life and lifetime profit in Korean Holstein. Asian-Australian. J. Anim. Sci. 26:1511-1517

Faid-Allah, E., E. Ghoneim, \& A. H. M. Ibrahim. 2016. Estimated variance components and breeding values for pre-weaning growth criteria in Romney sheep. JITV. 21(2):73-82.
Faraji-Arough, H., A. A. Aslaminjad, \& H. Farhangfar. 2011. Estimation of genetic parameter and trends for age at first calving and calving interval in Iranian Holstein cows. J. Agri. Sci. 7:79-87.

Filho, R. D. T., R. P. Torres, S. Lopes, C. S. Pereira, R. F. Euclydes, C. V. De Araujo, \& M. Silva. 2005. Genetic trends in the performance and reproductive traits of pig. Gen Molec Bio. 28:97-102.

Gunawan, A, R. Sari, Y. Parwoto, \& M. J. Uddin. 2011. Non genetic factors effect on reproductive performance and preweaningmortality from artificially and naturally breed of Bali cattle J. Indonesian. Trop. Anim. Agric. 36:1-8.

Gunawan, A, K. Jamal, \& C. Sumantri. 2008. Pendugaan bobot badan melalui analisis morfometrik dengan pendekatan regresi terbaik Best Subset pada domba garut tipe pedaging, tangkas dan persilangannya. Majalah Ilmiah Peternakan. 11(1):1-6

Hakim, L., V. M., A. Suyadi, Nurgiartiningsih, Nuryadi, \& T. Susilawati. 2007. Model recording dan pengolahan data untuk program seleksi sapi Bali. Sains Peternakan. 5(2):39-46.

Hare, E. H. D., Norman, \& J. R. Wright. 2006. Trend in calving ages and calving intervals for dairy cattle breed in the United States. J. Dairy. Sci. 89:365-370.

Hardjosubroto, W. 1994. Aplikasi Pemuliabiakan Ternak di Lapangan. Jakarta (ID): Gramedia Widiasarana Indonesia.

Ibrahim, M. A. M., S. A. M. Rushdi H. E., Abdel-Salam, \& S. Abou-Bakr. 2009. Genetic and phenotypic trends of calving interval and age at first calving in a commercial Holstein Herd. Egyptian J. Anim. Prod. 46(2):103-112.

Karnaen. 2008. Pendugaan heritabilitas, korelasi genetic dan korelasi fenotipik sifat bobot badan pada sapi Madura. J.Indon.Trop.Anim.Agric. 33(3): 191-196

Konkurea, T, S. Koonawootrittriron, M. A. Elzo, \& T. Suwanasopee. 2017. Genetic parameters and trends for daughters of imported and Thai Holstein sires for age at first calving and milk yield. Journal Elsevier. Agriculture and Natural Resources. 51:420-424.

Kaygisiz, A. 2013. Estimation of genetic parameters and breeding values for dairy cattle using test-day milk yield records. J Anim Plant Sci. 23(2):345-349.

Lee, J. H., K. D. Song, K. H. Lee, K. H. Cho, H. C. Park, \& K. D. Park. 2015. Genetic parameters of reproductive and meat quality traits in korean berkshire pigs. Asian Australian J Anim Sci. 28(10):1388-1393

Lopez, B.I., S. Ju-Hwan, K. Seo, \& D. Lim. 2019. Estimation of genetic parameters for reproductive traits in Hanwoo (Korean Cattle). Animals. 9:715.

Nuryadi, \& S. Wahjuningsih. 2011. Penampilan reproduksi sapi Peranakan Ongole dan Peranakan Limousin di Kabupaten Malang. Ternak Trop. 12:76-81.

Prihandini, P. W., L. Hakim, \& V. M. A. Nurgiartiningsih. 2011. Seleksi pejantan berdasarkan nilai pemuliaan pada sapi peranakan ongole (PO) di loka penelitian sapi potong Grati-Pasuruan. J. Ternak Tropika. 1:97-107. 
Riyanto, J., Lutojo, \& D. M. Barcelona. 2015. Kinerja reproduksi induk sapi potog pada usaha peternakan rakyat di Kecamatan Mojogedang. Sains Peternakan. 13(2):73-79.

Salem, M., \& M. Hammoud. 2016. Estimates of heritability, repeatability and breeding value of some performance traits of Holstein cows in Egypt using repeatability animal model. Egyptian J Anim Prod. 53:147-152.

Siswanto, M., N. W. Patmawati, N. N. Trinayani, I. N. Wandia, \& I. K. Puja. 2013. Penampilan reproduksi sapi Bali pada peternakan intensif di instalasi pembibitan Pulukan. J Ilmu dan Kesehatan Hewan. $1: 11-15$.

Solemani-Baghshah, S., S. Ansari-Mahyari, E. Mohamad-Ali, \& H. A. Nanaei. 2014. Estimation of genetic and phenotypic trends for age at first calving, calving interval, days open and number of inseminations to conception for Isfahan Holstein cows. Int. J. Adv. Biol. Biom. Res. 2(5):1307-1314.
Sonbait, L. Y., K. A. Santoso, \& Panjono. 2011. Evaluasi program pengembangan sapi potong gaduhan melalui kelompok Lembaga mandiri yang mengakar di masyarakat di Kabupaten Manokwari Papua Barat. Buletin Peternakan. 35(3):208-217.

Warwick, E. J., J. M. Astutik, \& W. Hardjosubroto. 1990. Pemuliaan Ternak. Yogyakarta (ID): Penerbit Gadjah Mada University Press.

Yulyanto, C. A., T. Susilawati, \& M. N. Ihsan. 2014. Penampilan reproduksi sapi Peranakan Ongole (PO) sapi Peranakan Limousin di Kecamatan Sawoo Kabupaten Ponorogo dan Kecamatan Tugu Kabupaten Trenggalek. Jurnal Ilmu-Ilmu Peternakan. 24(2):49-57.

Zambrano, J. C., \& J. Echeverri. 2014. Genetic and environmental variance and covariance parameters for some reproductive traits of Holstein and Jersey cattle in Antioquia (Colombia). R Bras Zootec.43:132-9.

Zishiri, O. T., S. W. P. Cloete, J. J. Oliever, \& K. Dzama. 2010. Genetic trends in South African terminal sire sheep breeds. S. Afr. J Anim Sci. 40(1):458. 